\title{
Salivary volume in the mouth immediately before and after swallowing in children
}

\author{
Shigeru Watanabe ${ }^{*}$, Yukiko Yamamura ${ }^{1}$, Aiko Hoshiai ${ }^{1}$, Shiho Morishita ${ }^{1}$, Aiko Machiya ${ }^{2}$, Satoru Matsuda ${ }^{2}$, Takahiro Shimojima ${ }^{1}$ and \\ Iwai Tohnai ${ }^{1}$ \\ ${ }^{1}$ Meikai University School of Health Sciences, Department of Oral Health Sciences, Akemi 1, Urayasu, Chiba 279-8550, Japan \\ ${ }^{2}$ Meikai University School of Dentistry, Department of Restorative and Biomaterials Sciences, Division of Oral Rehabilitation of Sciences, Keyakidai 1-1, Sakado, \\ Saitama 350-0283, Japan
}

\begin{abstract}
Studies on oral salivary clearance in adults have clarified values, such as oral salivary volume immediately before and after swallowing and saliva volume per swallow. However, studies have not been conducted in children with different unstimulated salivary flow rates and oral volumes. In the present study, we investigated salivary clearance in five-year-old children and compared it with caries incidence.

The amount of saliva remaining in the mouth immediately after swallowing $(\mathrm{X})$ was determined by comparing the potassium concentration in the subject's unstimulated saliva and in the diluted saliva obtained after rinsing the oral cavity with distilled water immediately after swallowing. The amount of saliva swallowed per swallow $(Z)$ was determined by dividing the subject's unstimulated saliva volume by the physiological number of swallows. The amount of saliva in the mouth immediately before swallowing $(\mathrm{Y})$ was calculated as $\mathrm{Y}=\mathrm{X}+\mathrm{Z}$. After the experiments, the oral conditions of the subjects were examined and the caries incidence (dmf index) was calculated. The subjects were 20 five-year-old children (10 boys and 10 girls).

The mean unstimulated salivary flow rate was $0.24 \pm 0.13 \mathrm{~mL} / \mathrm{min}$. The mean oral saliva volumes immediately before and after swallowing were $0.52 \pm 0.14 \mathrm{~mL}$ and $0.36 \pm 0.12 \mathrm{ml}$, respectively. The mean swallowing frequency was $1.7 \pm 0.5$ swallows $/ \mathrm{min}$, and the swallowing saliva volume was $0.14 \pm 0.1 \mathrm{~mL}$ per swallow. The oral saliva volume immediately before and after swallowing was approximately $50 \%$ of that in adults. No significant relationship was found between each value and the dmf index.
\end{abstract}

\section{Introduction}

Dawes [1] used a siphon to explain the mechanism by which oral stains are removed. According to Dawes' computer simulation [1], the faster the unstimulated salivary flow rates and the lower the amount of saliva in the mouth immediately before and after swallowing, the better the saliva clearance efficiency. Lagerlöf et al. [2] determined the amount of saliva in the mouth immediately before and after swallowing, the number of swallows per minute, and the amount of saliva swallowed with each swallow in adults. The study demonstrated a significant correlation between the amount of saliva retained immediately after swallowing and the individual's caries experience.

On the other hand, little research has been done on salivary clearance in children, who differ significantly from adults in terms of salivary flow rate and dentition $[3,4]$. In the present study, we followed the method of Lagerlöf et al. [2] to determine the saliva volume before and after swallowing and the volume per swallow in children and compared the values with that in adults.

\section{Subjects and methods}

\section{Subjects}

The subjects included in the study were 20 five-year-old children (10 of each gender) with good physical health, no abnormalities of the jaw and oral system, and a normal deciduous dentition.

\section{Oral saliva volume immediately after swallowing $(\mathrm{X})$}

Unstimulated saliva was collected employing the commonly used method for collection [5], and the concentration of potassium chloride (Ci) was measured. The subjects were instructed to perform a fivesecond oral rinse with $3 \mathrm{~mL}$ of distilled water immediately following a swallow and then expectorate it into a container to be weighed. The potassium concentration of the mixture of distilled water and saliva was then measured (Cf). Five different measurements were obtained from each subject, and each value was substituted into the following equation to obtain $\mathrm{X}$ : The potassium concentration was measured using an atomic absorption spectrophotometer (Shimadzu, Japan).

$$
\begin{aligned}
& \mathrm{X} \times \mathrm{Ci}=(\mathrm{V}+\mathrm{X}) \times \mathrm{Cf} \\
& \mathrm{X}=\text { saliva volume immediately after swallowing } \\
& \mathrm{Ci}=\text { Potassium concentration in unstimulated saliva } \\
& \mathrm{V}=\text { amount of distilled water used to rinse the mouth }
\end{aligned}
$$

${ }^{\star}$ Correspondence to: Shigeru Watanabe, Meikai University School of Health Sciences, Department of Oral Health Sciences, Akemi 1, Urayasu, Chiba 2798550, Japan, E-mail: swatanabe@meikai.ac.jp

Key words: salivary clearance, unstimulated salivary flow rate, swallowing frequency, oral saliva volume

Received: December 12, 2020; Accepted: January 04, 2021; Published: January 07,2021 
$\mathrm{Cf}=$ potassium concentration in the diluted saliva that was rinsed and expectorated

\section{Swallowing frequency and the amount of saliva in the mouth immediately before swallowing (Y)}

For the swallowing frequency, the cuff of a pediatric sphygmomanometer (Acoma, Japan) was fixed to the larynx, and the movement of the larynx during swallowing was recorded by a recorder (Hitachi, Japan) via a transducer (Medical Engineering, Japan) and amplifier (Medical Engineering, Japan) along with an animation software (Hitachi, Tokyo, Japan). An animation of the movement was displayed during the measurement, and the physiological swallowing frequency was recorded for $5 \mathrm{~min}$. The unstimulated saliva volume per minute was divided by the number of swallows per minute to obtain the saliva volume per swallow $(Z)$. The amount of saliva immediately before swallowing $(\mathrm{Y})$ was calculated as $\mathrm{Y}=\mathrm{X}+\mathrm{Z}$. All experiments were conducted between 2:00 p.m. and 4:00 p.m.

The reproducibility of the amount of saliva in the mouth immediately after swallowing was measured five times, and the coefficient of variation was calculated. Student's t-test was used for comparison between the genders, and the significance level was set at less than $5 \%$.

\section{Dental caries inspection}

After each experiment, the relationship between the subjects' dmf index and the results of each experiment was examined.

\section{Results}

The unstimulated salivary flow rate and oral salivary volume before and after swallowing are shown in Table 1. With respect to gender, there were no significant differences in the mean values of the following items; therefore, the mean values of 20 subjects are displayed. The unstimulated salivary flow rates ranged from 0.04 to $0.52 \mathrm{~mL} / \mathrm{min}$, with a mean value of $0.24 \pm 0.13 \mathrm{~mL} / \mathrm{min}$. The mean value of saliva volume retained in the mouth immediately after swallowing was $0.36 \pm$ $0.12 \mathrm{~mL}$. The coefficient of variation was $15.0 \%$. The mean potassium concentration in the unstimulated saliva was $20.09 \pm 3.72 \mathrm{mmol} / \mathrm{L}$. The mean number of swallows was $1.7 \pm 0.5 /$ minute. The mean volume of saliva in the mouth prior to swallowing was $0.52 \pm 0.14 \mathrm{~mL}$.

The mean $\mathrm{dmf}$ index of the subjects was $0.41 \pm 0.22$ for boys and $0.52 \pm 0.31$ for girls, and there was no significant relationship between these values and the above values.

\section{Discussion}

The measured volume of saliva immediately before swallowing was $0.52 \mathrm{~mL}$ in children. The volume of saliva per swallow was approximately $0.14 \mathrm{~mL}$, and the volume of saliva immediately after swallowing was approximately $0.36 \mathrm{~mL}$. Once swallowed, a volume of $0.14 \mathrm{~mL}$ is required before another swallow occurs, which is approximately $35 \mathrm{~s}$

Table 1. Measurements of oral saliva volume immediately before and after swallowing and factors related to it $(\mathrm{n}=20)$

\begin{tabular}{|c|c|c|}
\hline & Mean \pm S.D & Range \\
\hline Saliva after swallowing $(\mathrm{mL})$ & $0.36 \pm 0.12$ & $0.14-0.71$ \\
\hline Saliva before swallowing $(\mathrm{mL})$ & $0.52 \pm 0.14$ & $0.24-0.84$ \\
\hline Unstimulated salivary flow rate $(\mathrm{mL} / \mathrm{min})$ & $0.24 \pm 0.13$ & $0.04-0.52$ \\
\hline Swallowing frequency $($ times $/ \mathrm{min})$ & $1.7 \pm 0.5$ & $0.7-2.3$ \\
\hline Volume of saliva swallowed per swallow $(\mathrm{mL})$ & $0.14 \pm 0.10$ & $0.11-0.21$ \\
\hline Potassium concentration $(\mathrm{mmol} / \mathrm{L})$ & $19.8 \pm 3.9$ & $17.9-22.7$ \\
\hline
\end{tabular}

after the previous swallow, based on the average unstimulated salivary flow rates of the subjects (approximately $0.24 \mathrm{~mL}$ ). In other words, the average amount of saliva in the mouth increased or decreased between $0.52 \mathrm{~mL}$ and $0.36 \mathrm{~mL}$ in $35 \mathrm{~s}$. On the other hand, the actual number of swallows in this study showed that on an average, swallowing occurred once every $35 \mathrm{~s}(1.7 \pm 0.5$ swallows/minute), indicating that the mean time obtained from calculations and the mean value from actual measurements were consistent.

Comparing the present results in children with those in adults [2], the rate of unstimulated salivary flow rates in children was approximately $29 \%$, the volume of saliva immediately after swallowing was approximately $51 \%$, and the volume of saliva immediately before swallowing was approximately 49\%. Lagerlöf et al. [2] and Kapila et al. [6] reported single swallow volumes in adults, but not in children. In the former study, the mean swallowing frequency was $2.3 \pm 1.3$ swallows/ min and the mean swallowing volume was $0.3 \pm 0.2 \mathrm{~mL}$ (unstimulated salivary flow rate: $0.49 \pm 0.23 \mathrm{~mL} / \mathrm{min}$ ). In the latter case, the swallowing frequency was $1.2 \pm 0.2 \mathrm{swallows} / \mathrm{min}$, and since the swallowing volume was not stated, it was calculated from the unstimulated salivary flow rate $(0.38 \pm 0.04 \mathrm{~mL} / \mathrm{min})$ to be approximately $0.31 \mathrm{~mL}$. Thus, both reports showed differences in unstimulated salivary flow rates and swallowing frequency, but almost equal values for the amount swallowed per swallow. Jones et al. [7] determined the volume of sips taken when drinking a glass of water in children ( 1 to 3 years) and adults and found that children accounted for approximately $25 \%$ of the volume of sips taken by adults. It has also been reported that there is a high correlation between the physiological frequency and volume of swallowing, and the rate of saliva secretion $[6,8]$. Therefore, in this study, the subjects' salivary flow rate was slower than that of adults, which may indicate that they swallowed less per swallow than adults.

In this study, salivary potassium concentration was used as a marker to determine the amount of saliva retained after swallowing. Salivary potassium concentration is not easily affected by the salivary flow rate [9] and is relatively easy to measure. The mean salivary potassium concentration in adults has been reported to be approximately 21 $\mathrm{mmol} / \mathrm{L}$ [5], however, in five-year-old children, it was estimated to be $20.1 \pm 3.7 \mathrm{mmol} / \mathrm{L}$, and there was no significant difference between adults and children.

In order for the formula to determine the amount of oral saliva retained after swallowing to be valid by diluting the salivary potassium concentration, the salivary flow rate must be zero during the fivesecond mouth-rinsing. If we calculate the amount of saliva secreted during these $5 \mathrm{~s}$ from the one-minute unstimulated salivary volume of the subjects in this study, it is approximately $0.02 \mathrm{~mL}$, which can be considered to be zero according to the method used in this study.

The difference between salivary volumes measured in subjects before and after swallowing was relatively small compared to the results of experiments conducted in adults, which may be attributed to the influence of teeth and dental morphology in adults, but less so in deciduous dentition. The method of dilution was expected to be somewhat difficult for children; therefore, the experiment was conducted after several practice sessions. The coefficient of variation for this experiment was $15.0 \%$, which was slightly less accurate than that for adults (13.5\%).

Lagerlöf et al. [2] reported a correlation between oral saliva volume immediately before and after swallowing and caries experience in adults, but no relationship was found in children. This may be due to the small number of cases. 


\section{Conclusion}

The oral salivary volume immediately before and after swallowing in five-year-old children with deciduous dentition was approximately $50 \%$ of that in adults. There was no significant relationship between these values and the dmf index.

\section{Acknowledgments}

This study was partially supported by the 2020 Miyata Research Grant from Meikai University.

\section{References}

1. Dawes C (1983) A mathematical model of salivary clearance of sugar from the oral cavity. Caries Res 17: 321-334. [Crossref]

2. Lagerlöf F, Dawes C (1984) The volume of saliva in the mouth before and after swallowing. J Dent Res 63: 618-621. [Crossref]
3. Watanabe S, Dawes C (1990) Salivary flow rate and salivary film thickness in five-yearold children. J Dent Res 69: 1150-1153. [Crossref]

4. Watanabe S (1992) Salivary clearance from different regions of the mouth in children. Caries Res 26: 423-427. [Crossref]

5. Dawes C (1987) Physiological factors affecting salivary flow rate, oral sugar clearance, and the sensation of dry mouth in man. $J$ Dent Res 66: 648-653. [Crossref]

6. Kapila YV, Dodds WJ, Helm JF, Hogan WJ (1984) Relationship between swallow rate and salivary flow. Dig Dis Sci 29: 528-533.

7. Jones DV, Work CE (1961) Volume of a swallow. Am J Dis Child 102: 427.

8. Lagerlöf F, Dawes C (1985) The effect of swallowing frequency on oral sugar clearance and $\mathrm{pH}$ changes by streptococcus mitior in vivo after sucrose ingestion. J Dent Res 64: 1229-1232. [Crossref]

9. Jenkins GN (1978) The physiology and biochemistry of the mouth.4th ed., Oxford Blackwell, p.286.

Copyright: (C2021 Watanabe S. This is an open-access article distributed under the terms of the Creative Commons Attribution License, which permits unrestricted use, distribution, and reproduction in any medium, provided the original author and source are credited. 